\title{
INOVAÇÃO E EMPREENDEDORISMO: UM CASO NO SETOR PÚBLICO
}

\section{INNOVATION AND ENTREPRENEURSHIP: A CASE IN THE PUBLIC SECTOR}

\author{
Thatiana Stacanelli Teixeira \\ Graduada em Administração Pública pela Universidade Federal de Lavras (UFLA) \\ Lavras, MG, Brasil \\ Email: stacanellithati@gmail.com \\ Daniela Meirelles Andrade \\ Docente efetiva da Universidade Federal de Lavras (UFLA) \\ Lavras, MG, Brasil \\ Email: daniela.andrade@dae.ufla.br \\ Valderí de Castro Alcântara \\ Doutorando pela Universidade Federal de Lavras (UFLA) \\ Lavras, MG, Brasil \\ Email: valderidecastroalcantara@gmail.com \\ Naiara Kasmin de Oliveira \\ Graduada em Administração Pública pela Universidade Federal de Lavras (UFLA) \\ Lavras, MG, Brasil \\ Email: naiarakasmin@yahoo.com.br
}

\section{RESUMO}

Neste trabalho analisa-se o potencial e alcance da ação empreendedora na Administração Pública Brasileira. Este estudo de caso aborda dois fenômenos associados ao empreendedorismo: a inovação e o intraempreendedorismo. Foi realizado um estudo de caso único, em que a secretária responsável pela Secretaria de Cultura do município de Minas Gerais forneceu os dados para a estruturação do caso através de uma entrevista semiestruturada. Foi possível identificar traços marcantes dos dois fenômenos abordados neste estudo, sendo que ao unir as informações adquiridas através da entrevista junto ao conteúdo didático transcrito durante todo o trabalho, foi possível validar o conhecimento sobre o assunto de empreendedorismo no setor público e a realização deste na prática.

Palavras-chave: Ação empreendedora. Inovação. Intraempreendedorismo. Empreendedorismo Público. Empreendedorismo.

\begin{abstract}
This paper analyzes the potential and scope of entrepreneurial action in the Brazilian Public Administration. This essay is subdivided with focus on two phenomena associated with entrepreneurship: innovation and intra-entrepreneurship. A single case study was conducted in which the secretary responsible for the Culture Department of the city of Minas Gerais provided the data for structuring the case through a semi-structured interview. It was possible to identify striking features of the two phenomena addressed in this study, and by uniting the information acquired through the interview with the didactic content transcribed throughout the work, it was possible to validate the knowledge about the subject of entrepreneurship in the public sector and the practice.
\end{abstract}

Keywords: Entrepreneurial action. Innovation. Intrapreneurship. Public Entrepreneurship. Entrepreneurship. 


\section{INTRODUÇÃO}

Modificações administrativas como inovações e estratégias na gestão têm ocorrido dentro do setor público nos últimos anos, e estas tem proporcionado um aumento nas expectativas de sua modernização. Mediante isso, estratégias de empreendedorismo estão sendo aplicadas de forma a tornar o serviço mais eficiente e eficaz. Esse modelo de gestão busca induzir o empreendedor a deduzir oportunidades, sendo capaz de inovar e aperfeiçoar sua gestão. Nessa perspectiva, é fundamental que a Administração Pública busque por resultados, não visando o lucro, mas sim uma melhor forma de aplicação dos recursos, os quais devem buscar pelo progresso da qualidade de vida da sociedade. Entretanto, algumas dificuldades são constatadas na hora de gerir as estratégias no setor público, entre elas a legislação, a cultura organizacional e as limitações de recursos, mas isso não torna impossivel essa aplicabilidade. Dessa forma, empreender possui uma gama de conceitos, sendo relevante reconhecer que há problemas e obstáculos a serem superados, por meio da percepção de uma oportunidade para mudança, a qual deve estar aliada a um novo processo de aprender.

O empreendedorismo no setor público refere-se a um processo de aperfeiçoamento que resulta em atividades inovadoras, como o desenvolvimento de novos serviços, tecnologias, técnicas administrativas, aprimoramento de estratégias (VALADARES; EMMENDOERFER; MORAIS, 2014) e melhorias de processos já existentes. $O$ empreendedor tem como função reformular ou modificar um método ou maneira existente, podendo ate então criar algo novo. Estes atores podem fazer isso de diversas formas, sendo através de uma grande inovação renovando os métodos ou simplismente adicionando e/ou modificando minimamente a forma de trabalhar.

Nesse contexto, podemos considerar a ação empreendedora como elemento central do fenômeno do empreendedorismo, expressando-se em situações organizacionais, configuradas como oportunidades e transformações, que geram resultados organizacionais através da ação coletiva entre diferentes atores (ANDRADE; LIMA; BORGES, 2014). Assim, este trabalho tem como objetivo compreender como a gestora de uma Secretaria de Cultura de um município localizado no sul de Minas Gerais, juntamente com sua equipe, realizam ações empreendedoras e de inovações, baseando-se nas identificações ou criações de oportunidades.

O artigo está estruturado em seis partes, sendo: introdução, a qual contextualiza o estudo; referencial teórico, apresentando as principais abordagens utilizadas, expondo a natureza do empreendedorismo, as inovações e o empreendedorismo público; metodologia utilizada, sendo do tipo qualitativa descritiva com a realização de estudo de caso único, por meio de uma entrevista em profundidade e observação participante, realizando a análise de conteúdo para validação dos dados; descrição dos resultados, mostrando como a secretária conseguiu identificar oportunidades e as transformarem em ação, conseguindo empreender no setor público; por fim, as considerações finais que indicam a formação da ação empreendedora no setor público, a qual é capaz de proporcionar a inovação, por meio do desenvolvimento de oportunidades. 


\section{A NATUREZA DO EMPREENDEDORISMO}

Ao longo de vários séculos, a definição de empreendedorismo foi discutida por diversas vezes com o objetivo de estabelecer quais seriam as especificidades de seu agente social, o empreendedor. Empreendedor tem origem francesa, entre-preneur (FILION, 1997), e surgiu no século XII. Com a necessidade de evoluir a conceituação do termo, ao final do século XVII e início do século XVIII, Filion (1999, p. 18) descreveu a nova utilização do termo, sendo utilizado para referir-se à "pessoa que criava e conduzia projetos" e logo depois, sendo o termo utilizado para se referir ao seu agente social, o empreendedor, sendo aquele que assume riscos e começa algo novo.

O termo abordado teve seus estudos voltados para duas abordagens teóricas: a econômica e a comportamentalista. A abordagem econômica teve como fundador o econômico Richard Cantillon, compreendendo que empreendedor era aquele que aproveitava as oportunidades com a premissa de obter lucros, assumindo os riscos envolvidos (FILION, 1997, 1999). Cantillon também foi o primeiro a desenvolver uma visão clara sobre a função socioeconômica do empreendedor. Em sequência, veio Jean Baptista Say, sendo considerado o pai do empreendedorismo, caracterizando o empreendedor como um agente de mudança, agrupando ao seu conceito o termo inovação (FILION, 1997, 1999).

Escritores econômicos renomados como Smith, Mill e Baumol ampliaram o entendimento de empreendedorismo e apontaram que este poderia ser identificado como o idealizador da substituição de produtos retrógados por outros com perspectivas mais inovadoras e com um maior potencial de lucro. Enquanto economistas como Higgins, Penrose e Kirzner tratavam os empreendedores como pessoas que eram capazes de identificar as oportunidades de negócios (VALADARES; EMMENDOERFER; ALVES; MORAIS, 2012).

Mesmo com essas conceituadas atribuições, Sadler (2000) observou que a ideia de empreendedorismo pregada pelos economistas está associada à capacidade do homem, ao ser empreendedor, de inovar e de ter o potencial de contribuir para o desenvolvimento local da economia. Esses conceitos podem ter influências diretas ou indiretas no sistema de produção que estava em vigência na época dos clássicos da economia, o homos econômicus. Este se refere a um sistema de produção, onde o próprio indivíduo era considerado como uma extensão da máquina produtiva e dedicava grande parte de sua vida para a busca incansável pelo lucro (SADLER, 2000). Essa perspectiva ajudou alguns autores como Stevenson e Jarillo, Covin e Slevin, Cunningham e Lischeron e Bygrave a descreverem o perfil de um empreendedor, e baseado nas informações desses autores, Fllion (1997) sintetizou os pensamentos destes e concluiu que os empreendedores são fruto de seu ambiente.

Filion (1997) evidenciou que o espírito empreendedor pode ser desenvolvido e aflorado mediante a influência que a cultura empreendedora pode exercer na formação de um perfil empreendedor, tendo como indispensável para este afloramento, o ambiente onde o agente social está inserido. Ele é responsável por incitar o indivíduo a agir, de forma empreendedora, vencendo os desafios encontrados e autorrealizando-se. Mas a busca pela autorrealização pode acarretar problemas, em se tratando de empreendedor no setor público. Sadler (2000) destaca que esse indivíduo pode tornar-se um risco para a administração pública, devido ao fato de sempre querer buscar a realização de seu próprio objetivo, caracterizando este indivíduo 
como um camaleão dentro da organização pública, no sentido de que ocorrem mudanças de cores em razão do atendimento de seus objetivos particulares.

Em se tratando da influência da cultura no comportamento empreendedor, pode-se destacar, segundo Oliveira e Guimarães, (2004, p. 5) que variáveis como a crença religiosa, a experiência prévia no negócio, a influência e estímulos de familiares, amigos e mentores, a história de vida, o desemprego, além de demissões e outras experiências, são discutidas nas pesquisas de Bygrave, Shapero e Skol Young e Weber como fundamentais para representar elementos que poderiam agir como propulsores ou facilitadores do empreendedorismo (OLIVEIRA; GUIMARÃES, 2004).

De acordo com a teoria do psicólogo David McClelland (1961), o conceito de empreendedor está relacionado à necessidade de sucesso, reconhecimento, poder e controle. A partir dessas necessidades é que surge ou que se determina o comportamento e perfil do empreendedor, os quais são interligados. $O$ indivíduo que é considerado empreendedor possui características comportamentais empreendedoras bem definidas que ao se agrupar com outras propriedades, é possível diagnosticar o perfil empreendedor. 0 comportamento evidente para McClelland (1961) está relacionado à realização, sendo que a necessidade deste impele o indivíduo a buscar objetivos desafiantes, preocupando-se em fazer bem feito suas ações. Deve-se observar que os empreendedores públicos não podem ser instigados a agir pelas possíveis recompensas financeiras e de prestígios exuberantes, mas sim para o bem da coletividade, devido suas funções administrativas de sempre buscar pela coletividade.

Os empreendedores são dotados de atitudes inteligentes, sabem definir objetivos a serem alcançados e visualizar oportunidades. Nessa direção, Bueno, Leite e Pilatti (2004) entende que essas pessoas não acreditam em fracasso, sabem que existem os obstáculos e possuem disposição e coragem para enfrentálos, além de conseguirem ter uma atitude mental direcionada para a realização de suas vitórias.

Eles estão inseridos em instituições públicas e empresas privadas, onde em ambas há a possibilidade de associar esse fenômeno a outros fatores relevantes para o sucesso e aperfeiçoamento da ação empreendedora (VALADARES; EMMENDOERFER; MORAIS, 2014; ANDRADE; LIMA; BORGES, 2014). Como exemplo de fatores relevantes para o sucesso, temos a interferência da inovação nos processos empreendedores é um exemplo típico do sucesso deste termo, sendo que estas caminham juntas em busca do sucesso, e será apresentada na seção seguinte.

\section{Inovação e empreendedorismo}

O empreendedor é considerado o agente de inovações que ocorre tanto em organizações públicas quanto privadas, sendo ele o responsável por buscar e conduzir a inovação (ANDRADE; LIMA; BORGES, 2014). Segundo o autor Joseph, a vinculação de inovação e empreendedorismo refere-se a um método que ocorre nas suas mais diversas formas e meios, sem equívocos e sobrepujar, assim o empreendedor é o causador do forte impulso do capital, devido sua 'força destruidora e criativa' de novos mercados, serviços e produtos que carrega dentro de si (SCHUMPETER, 2002).

Joseph Schumpeter, no século XX, conceituou empreendedor como aquele que desafia ou destrói criativamente (FERNANDES; SANTOS, 2008), referindo-se a expressão "destruição criativa" com forte mérito, estando subentendido que o empreendedor é considerado um ser criativo e é a força motora do capital (MOTA COELHO, 2010). 
Visando a unificação da teorização sobre o tema Inovação, a Organização para a Cooperação e Desenvolvimento Econômico (OCDE) realizou a primeira edição do Manual de Oslo em 1990, com propostas e diretrizes para a coleta e interpretação de dados sobre a Inovação Tecnológica, contendo orientações e padronizações de conceitos existentes. A primeira versão em português foi divulgada pela FINEP em meio eletrônico em 2004, sendo a versão mais atualizada lançada em 2005. De acordo com o Manual, tudo que é lançado no mercado com mudanças e novidades é considerado uma inovação.

Conforme o Manual de Oslo (2004), as inovações podem ser classificadas em quatro abordagens, sendo elas: de produto, de processo, organizacional e de marketing. As inovações de produtos são desenvolvidas através de novas tecnologias e meios de produção, sendo maiores onde a economia é mais desenvolvida; inovações de processos têm por base as novas ideias referindo-se à adoção de métodos de produção novos ou melhorados; inovações organizacionais estão relacionadas às pessoas e ao meio organizacional; inovações de marketing referem-se à inovação de processo e métodos de marketing preexistentes. Elas podem também ser classificadas como; incrementais, quando é introduzido gradualmente melhorias e avanços nos métodos e produtos, ou até mesmo investimentos; ou radicais, quando as mudanças ocorrem de maneira abrupta (MANUAL DE OSLO, 2004).

De acordo com Gallouj (2002), é possível identificar seis modelos de processo de inovações. O primeiro refere-se à inovação radical, também classificada pelo Manual de Oslo. Este tipo de inovação relaciona-se com o desenvolvimento de um conjunto de características, as quais originam um novo produto, sendo que as características finais do produto ou serviço podem não se alterar significativamente. O segundo modelo é a inovação de melhoria que envolve mudanças na qualidade de certos fragmentos das bases de característica do produto, sem modificar as demais bases. Refere-se também ao aperfeiçoamento do produto com melhorias nas características finais. A inovação incremental, também abordada pelo Manual de Oslo (2004), trata-se da adição ou substituição de componentes existentes por outros inovadores, sendo um aperfeiçoamento das características finais do produto. O quarto modelo de inovação é a recombinação, a qual visa a dissociação ou a recombinação de vetores das características para formar um novo produto. O quinto modelo é a inovação por formalização que visa ordenar os atributos do produto, transfigurando em mais visíveis e padronizadas. A última inovação, é a ad hoc, que é conceituada como a construção conjunta entre o produtor/prestador do serviço e o cliente, a partir de uma solução apresentada para o problema identificado pelo cliente (GALLOUJ, 2002).

O protagonista da inovação é conhecido como intraempreendedor. O termo em inglês, intrapreneuring, foi utilizado pela primeira vez pelo francês Gifford Pinchot III para designar o agente responsável pela inovação na organização, independentemente de seu enquadramento, lugar ou momento (PINCHOT, 1985; DORNELAS, 2003).

O aprendizado e o conhecimento do espírito intraempreededor são considerados ferramentas indispensáveis para encarar as constantes e profundas mudanças tecnológicas e socioeconômicas encontradas atualmente. Ao envolver o agente do empreendedorismo com o processo de inovação, o sucesso ocorre como consequência da junção destes, sendo que ambos são indispensáveis para as organizações públicas e privadas. A inovação em serviço não constitui 'algo radical', mas sim um processo gradativo, um novo produto aqui, uma diretriz ali, um serviço público acolá (DRUCKER, 1998 apud ANDRADE; LIMA; BORGES, 2014). 


\section{Empreendedorismo público}

O empreendedorismo público pode ser visto como um processo de identificação e busca de oportunidades de indivíduos e/ou organizações, evidenciando a capacidade de inovação, tomada de riscos e proatividade (CURRIE et al., 2008). Esse empreendedor tende a provocar mudanças constantes no ambiente em que está inserido devido à procura por soluções inovadoras para os problemas organizacionais, sendo que este agente não possui laços emocionais a seus cargos e à classe em que se encontra (VALADARES; EMMENDOERFER; MORAIS, 2014).

Após estudarem algumas literaturas nacionais e internacionais, Valadares et al. (2012) concluem que as dimensões mais citadas dentro do conceito de empreendedor público são: inovação, proatividade e tomada de riscos. Para comprovar essas dimensões mais abordadas no setor público, pode-se destacar as diferenças entre empreendedores públicos e privados a partir das categorias apresentadas na Quadro 1, elaborado por Kearney et al. (2009, p. 29) apud Valadares et al. (2012).

Quadro 1. Diferenças entre o Empreendedorismo Público, Empreendedorismo Independente e no setor Privado.

\begin{tabular}{|c|c|c|}
\hline Categorias & $\begin{array}{c}\text { Empreendedorismo no setor } \\
\text { Público }\end{array}$ & $\begin{array}{c}\text { Empreendedorismo independente e } \\
\text { no setor privado }\end{array}$ \\
\hline Objetivos & $\begin{array}{l}\text { Grande diversidade e multiplicidade de objetivos; } \\
\text { grande conflito entre os objetivos (BENFIELD, } \\
\text { 1975) }\end{array}$ & $\begin{array}{l}\text { Objetivos mais claros e definidos; grande } \\
\text { consistência entre os objetivos (SADLER, } \\
\text { 2000) }\end{array}$ \\
\hline Autoridade & $\begin{array}{l}\text { Maior nível de autoridade e centralização do } \\
\text { controle (DOW NS, 1967; PUGH et al., 1969) }\end{array}$ & $\begin{array}{lcr}\text { Controle mais } & \text { democrático e e } \\
\text { descentralizado } & \text { (MILLER,1983; } \\
\text { CORNWALL e PERLM A N, 1990) }\end{array}$ \\
\hline $\begin{array}{l}\text { Processo de } \\
\text { Decisão }\end{array}$ & $\begin{array}{l}\text { Menor autonomia para tomada de decisão; menor } \\
\text { flexibilidade; mais restrição nos procedimentos e } \\
\text { atividades operacionais; transparência (RAYNEY } \\
\text { et al., 1976) }\end{array}$ & $\begin{array}{l}\text { Elevado grau de autonomia e flexibilidade } \\
\text { no processo de tomada de decisão; mais } \\
\text { participativo e independente (PEARCE e } \\
\text { DAVID, 1983) }\end{array}$ \\
\hline $\begin{array}{l}\text { Recompensas / } \\
\text { Motivação }\end{array}$ & $\begin{array}{l}\text { Baixos incentivos financeiros; sem redistribuição } \\
\text { de lucros (RAMA MURTI, 1986; MORRIS e } \\
\text { JONES, 1999). Baixo compromisso e satisfação } \\
\text { no trabalho (RHINEHART et al., 1969; } \\
\text { BUCHANON, 1974; RAYNEY, 1983; BOYNE, } \\
\text { 2002) }\end{array}$ & $\begin{array}{l}\text { Tomada de risco calculado; investimento } \\
\text { de capital próprio na empresa; elevados } \\
\text { incentivos financeiros; rentabilidade como } \\
\text { principal mecanismo para gerar renda } \\
\text { (RAMAMURTI, 1986; HORNSBY et al., } \\
\text { 2002). }\end{array}$ \\
\hline Inovação & $\begin{array}{l}\text { Atuam na busca por superar entraves burocráticos } \\
\text { e políticos que muitas vezes restringem as } \\
\text { inovações (SANGER e LEVIN, 1992) }\end{array}$ & $\begin{array}{l}\text { Atua na criação de valor através da } \\
\text { inovação e aproveitamento de } \\
\text { oportunidade; produção de recursos } \\
\text { existentes com maior potencial para a } \\
\text { criação de riqueza (CHURCHILL, 1992) }\end{array}$ \\
\hline Tomada de Risco & $\begin{array}{l}\text { Leva relativamente grandes riscos organizacionais } \\
\text { sem tomar grandes riscos pessoais (MORRIS e } \\
\text { JONES, 1999) }\end{array}$ & $\begin{array}{l}\text { Assume significativo risco financeiro e } \\
\text { pessoal, mas busca minimiza-los } \\
\text { (MCCLELLAND, 1961) }\end{array}$ \\
\hline Proatividade & $\begin{array}{l}\text { Utiliza todas as oportunidades para distinguir a } \\
\text { empresa pública e estilo de liderança do que é a } \\
\text { norma no setor público; entende o negócio, bem } \\
\text { como se apoia a oportunidade para crescimento. }\end{array}$ & $\begin{array}{l}\text { Segue uma } \\
\text { independentemente dos recursos que } \\
\text { eles controlam; relativamente irrestrita por } \\
\text { forças situacionais (TIMMONS,1994; } \\
\text { BATEMAN e CRANT,1993) }\end{array}$ \\
\hline $\begin{array}{l}\text { Financiamento } \mathrm{E} \\
\text { Lucratividade }\end{array}$ & $\begin{array}{l}\text { Não são orientados para o lucro; buscam obter } \\
\text { financiamentos para projetos; maior } \\
\text { disponibilidade de levantar capital; são motivados } \\
\text { por aspectos políticos e/ou objetivos sociais } \\
\text { (RAMAMURTI, 1986; MORRIS e JONES, 1999) }\end{array}$ & $\begin{array}{l}\text { Orientados pelo lucro; maior dificuldade } \\
\text { de acessar e obter financiamentos; } \\
\text { dificuldades em levantar capital (RA MA } \\
\text { MURTI, 1986) }\end{array}$ \\
\hline
\end{tabular}

Fonte: Kearney et al. (2009, p. 29) apud Valadares et al. (2012). 
Com a descrição das diferenças mencionadas no quadro 1, observa-se que as práticas de um setor para o outro torna-se delicada, em que segundo Valadares et al. (2012, p. 08) "é preciso conceber o empreendedorismo público como um construto em processo de formação". Mas a visão de empreendedorismo público ainda vem sendo muito discutida devido ao modelo gerencial existente na administração pública, sendo este cabível de muitos questionamentos e críticas.

Na visão de Drucker (1985), o empreendedorismo é uma forma de mudança e de o empreendedor buscar explorar novas oportunidades. Drucker ressalta que na administração pública o aspecto burocrático é evidente, então buscar essas oportunidades torna-se desafiador para o empreendedor. Mesmo com todas as barreiras encontradas no setor público, para Osborne e Gaebler (1992) os empreendedores públicos usam dos recursos disponíveis e constroem novas maneiras para maximização da produtividade e efetividade organizacional para prestar um serviço público eficiente e inovador ao cidadão.

\section{METODOLOGIA DE PESQUISA}

Uma pesquisa do tipo descritiva se baseia em procedimentos formais e objetivos claramente definidos e, ainda são bem estruturadas e direcionadas para a solução de problemas ou para o diagnóstico de alternativas de cursos de ação. Esse tipo de pesquisa tem por objetivo fornecer dados ao pesquisador sobre as características de grupos, estimativas de determinadas características e averiguar a existência de relações (MATTAR, 1993). Nisso, a presente pesquisa se define como de tipo descritiva.

Adiante, a pesquisa caracteriza-se por ser um estudo de caso único, que segundo Stake (2000), tem por objetivo utilizar apenas um único caso. Tal tipo de estudo é apropriado para averiguar se as proposições de uma teoria são corretas, quando o estudo é considerado raro ou que não exista muitas situações semelhantes para que sejam realizados outros estudos comparativos (STAKE, 2000).

O estudo em questão é considerado como uma pesquisa de natureza qualitativa. Kirk e Miller (1986) argumentam que nesse tipo de pesquisa, os dados são adquiridos por meio de perguntas abertas, sendo realizadas em entrevistas em grupos ou individuais, em profundidade e em testes projetivos. Ela se enquadra nessa metodologia de pesquisa devido à realização de uma entrevista semiestruturada em profundidade com a secretária responsável pelos assuntos culturais do município, com o objetivo de adquirir informações necessárias para a elaboração do estudo. Além da entrevista, houve observação participante de um dos pesquisadores durante aproximadamente seis meses. As observações foram tomadas em bloco de notas, não sistematizadas e auxiliaram na análise dos dados, a partir da possibilidade de triangular técnicas.

O roteiro de entrevista foi elaborado seguindo a seguinte lógica: histórico da Secretaria, estruturação interna, leis necessárias, atuação da gestora (em eventos e internamente), aquisição de recursos, planejamento na gestão, eventos realizados pela Secretaria, pontos fortes e pontos fracos da organização e de sua gestão. Já a observação participante objetivou comprovar os mesmos aspectos, porém com um enfoque na observação e na percepção dos fatos. A análise dos dados foi feita pela análise de conteúdo, segundo Vergara (2006) e Bardin (2007), refere-se a uma técnica de tratamento de dados, que através de procedimentos sistemáticos e objetivos de descrição do conteúdo das mensagens, enseja a interferência de conhecimentos relativos às condições variáveis compreendidas destas mensagens, identificando o que está 
sendo dito a respeito de determinado tema. As categorias analisadas foram 'inovação' e 'empreendedorismo no setor público'.

\section{ANÁLISE DOS RESULTADOS}

\section{Secretaria de cultura: um caso de inovação e empreendedorismo no setor público}

A Secretaria de Cultura de um município localizado no sul de Minas Gerais, que existe há aproximadamente três anos, foi criada por iniciativa do ex-prefeito local devido a uma sensibilidade administrativa em perceber que os assuntos ligados à cultura mereciam melhor atenção e gerenciamento. Antes do surgimento desta, os assuntos relacionados à cultura eram tratados diretamente pela Secretaria de Educação e Cultura, embora os assuntos e ações que são tratadas em ambas as Secretarias sejam intercomplementares, o desmembramento se tornou necessário para uma melhor gestão de assuntos culturais e, consequentemente, um maior engajamento da administração nestes assuntos.

A gestora assumiu o cargo mediante convite do então prefeito, em função do desmembramento. Segundo relatos, a secretária possuía conhecimentos na área de educação em razão de sua profissão como professora e seria capaz de assumir o cargo com a expectativa de conciliar eventos culturais promovidos por ela e sua equipe com um foco direcionado à aprendizagem e educação. $O$ convite para a ocupação do cargo foi tratado como um grande desafio, por parte da secretária, já que uma de suas preocupações e, consequentemente expectativas, era empreender, ou seja, transformar a secretaria de cultura em uma secretaria de sucesso.

Logo após a ocupação do cargo, a secretária e sua equipe tiveram grandes dificuldades ao estruturar o órgão, em decorrência da inexistência de formalidades de ações do passado, ou seja, de registros das atividades programadas e executadas pela antiga Secretaria de Educação e Cultura, pois o caminho percorrido não havia sido registrado, nem em forma de documentação e nem em forma de registro. Apesar da falta de documentação e de história da secretaria, a secretária soube lidar com as dificuldades, contornando-as por meio da criação de procedimentos formalizados e necessários em cada órgão integrante à Secretaria de Cultura.

Em sua percepção, alguns proveitos foram tirados das dificuldades encontradas, sendo que os obstáculos que dificultaram a implantação da repartição trouxeram benefícios para sua administração, assim como a possibilidade de programar uma gestão de acordo com os seus princípios e critérios administrativos, moldando os integrantes de sua equipe para enfrentar possíveis desafios e realizar um trabalho satisfatório para toda a administração.

O ineditismo da secretaria teve início em 2013, porém com a falta de documentos vinculados à cultura, houveram grandes trabalhos para atender às necessidades de formalizações e para isso, havia necessidade de encaminhar leis para os superiores. Para tanto, a secretária e sua equipe procuraram pautar-se no Plano Nacional de Cultura para estabelecer suas metas, objetivos e finalidades como Secretaria de Cultura. Fez-se então uma releitura deste Plano de forma a adaptar a necessidade local e moldou-se às exigências normativas para o funcionamento da nova Secretaria de Cultura. 
O primeiro passo foi a legalização da existência da Secretaria de Cultura. Para tanto, encaminhou-se o decreto de Lei de Criação da referida secretaria, o qual estabelece os objetivos, finalidades gerais e o organograma, bem como a Lei da Cultura do Município, a Lei do Conselho Municipal de Cultura e a lei para gerir o Fundo Municipal de Cultura. Desta forma, delineou-se a organização da secretaria, bem como a estrutura em termos legais e de recursos humanos. Para conseguir ter acesso à recursos e repasses de verbas federais, a Secretaria de Cultura criou o Conselho Municipal de Cultura, a partir do qual passou-se a integrar como participante do Fundo Nacional de Cultura, integrando o município ao Sistema Nacional de Cultura (SNC). O SNC é o órgão federal financiador que traz os recursos para a cultura local. Outra iniciativa da secretária nesse sentido, foi à prestação de contas do patrimônio municipal ao ICMS Cultural (Imposto sobre Circulação de Mercadorias e Serviços) através do qual recebe uma pontuação que irá determinar o montante a ser repassado para o município, que por sua vez é realizado de dois em dois anos. Essas práticas de acesso às verbas federais para a cultura não eram realizadas por outras gestões municipais, mas foi adaptada de outras cidades que possuíam o financiamento do SNC e aplicavam a verba recebida aos projetos culturais de forma bem-sucedida. Foi a partir do conhecimento de práticas realizadas em outras cidades que a então secretária vislumbrou tal possibilidade de inovação para o município.

Após superar as dificuldades de legalização, surgiu-se outro entrave para concretizar o sucesso e eficiência da Secretaria, sendo a capacitação e distribuição de tarefas da equipe, já que uma de suas metas era criar uma Secretaria de Cultura que destacasse diante as outras da região e servisse de exemplo para as demais. Para concretizar seu sonho, a secretária se empenhou em oferecer e ministrar minicursos destinados à capacitação e aprendizagem de sua equipe, com o propósito de reforçar os objetivos e as ações planejadas. As reuniões eram feitas semanalmente, e envolvia todos os funcionários ligados à Secretaria. A participação dessas pessoas é considerada imprescindível para que haja a possibilidade de realizar uma avaliação dos eventos e oficinas oferecidas pela Secretaria, pois é através desse feedback que a gestora identifica algumas falhas que possam ser reformuladas, bem como identifica os pontos de sucesso que deveriam ser implementados nos próximos eventos.

Com o passar do tempo e ao implantar as leis elaboradas e adaptadas por ela e sua equipe, foram diagnosticadas algumas dificuldades que não dependiam mais da área administrativa e sim, da população local. A dificuldades para a composição do Conselho Municipal de Cultura conforme previsto no Plano Nacional de Cultura, era uma grande dificuldade, pois este apresenta grande detalhamento do Plano Nacional, separando e enumerando a quantidade de representantes de cada área. A equipe teve dificuldades em encontrar artistas e profissionais qualificados para todas as áreas elencadas no Plano Nacional, e mediante a esta dificuldade a secretária em parceria com sua equipe optou por reformular a lei de criação na parte de composição do Conselho Municipal, pautada no distanciamento da lei e a realidade local. Outro problema é a rigidez das leis que tornam o sistema muito burocratizado, assim as cidades de menor porte, tem dificuldade de atender todas as exigências, inclusive de editais para aprovação de recursos. 


\section{Inovação empreendedora}

Analisando o caso, verifica-se traços de empreendedorismo acrescidos de inovações, os quais revolucionaram a Secretaria de Cultura da cidade localizada no sul de Minas Gerais, favorecendo toda a comunidade local e agregando bons resultados para a administração e história cultural do município.

De acordo com as informações cedidas pela gestora da Secretaria de Cultura, a abertura da repartição foi diagnosticada como um desafio inicial, sendo que era preciso constituir a Secretaria desde o início, e como uma boa gestora com visão empreendedora aflorada, ela não deixou se abalar pela quantidade de trabalho e desafios que estavam à sua espera. Segundo a secretaria responsável, esse seria o maior desafio de sua carreira até o momento e os desafios que iria encontrar serviriam de trampolim para alavancar cada vez mais a nova secretaria que estava surgindo. As inovações estavam presentes desde sua abertura, sendo que esta já é a primeira inovação identificada, tanto para o município quanto para o quadro estrutural da administração pública local. De acordo com o Manual de Oslo (2004), esta se classificaria como uma inovação organizacional, já que está relacionada às pessoas e ao meio organizacional.

Para Gallouj (2002) inovação é à criação de um serviço ou produto ou mesmo o aperfeiçoamento de algo já existente. Segundo o autor, esta pode ser compreendida em inovação radical, de melhoria, por recombinação e formalização. A Inovação radical, de acordo com Gallouj (2002) e Manual de Oslo (2004) é a que ocorre a criação de um novo conjunto de vetores e de características, os quais configuram um novo produto ou serviço. Este tipo de inovação foi identificado no caso em análise e pode ser evidenciado no momento em que a secretária deslumbra a real importância de que assuntos relacionados à Cultura mereciam ser geridos de forma específica e não conjunta com outra repartição como a da educação. Embora as ações em ambas as secretarias sejam intercomplementares, os assuntos culturais mereciam um gerenciamento próprio com enfoque mais direcionado.

A Inovação de melhoria é aquela em que ocorre mudança na qualidade de alguns componentes dos vetores de característica do produto ou serviço, mas sem alterar a estrutura dos demais vetores (GALLOUJ, 2002), ocorre apenas aperfeiçoamento de competências dos produtos ou serviços, que por consequência geram melhorias nas características finais dos mesmos. Essa categoria pode ser observada durante a entrevista quando a gestora afirma que realiza capacitações como cursos e palestras para sua equipe, sendo ela mesma responsável muitas vezes por ministrar as palestras, deixando claro que a equipe precisa estar em constante reciclagem de aprendizado, além de definir as tarefas e responsabilidades de cada membro que compõe a equipe.

A Inovação por recombinação acontece quando elementos dos vetores de características dos produtos e dos serviços são combinados ou desagregados para gerar um novo produto/serviço (GALLOUJ, 2002). Observou-se essa característica quando a secretária revelou que está trabalhando e projetando melhorias para transformar o evento 'Mostra Cultural' que já acontece no município em um Festival de Cultura, com nova programação e linhas culturais.

A Inovação por formalização (GALLOUJ, 2002) sucede pela documentação das características dos serviços, fazendo com que eles se tornem mais visíveis e padronizados. Esse tipo de inovação é uma das primeiras coisas que a gestora realizou ao assumir a Secretaria, legalizando-a. Foram instituídas leis, como a da Criação Secretaria da Cultura do Município e do Fundo Municipal de Cultura. 
O processo de inovação aliado ao empreendedorismo no setor público está presente desde a inauguração da Secretaria até a execução de suas ações. Ao dar início, foi preciso estruturar e formalizar a Secretaria da Cultura através da criação de leis, pois nada disso havia sido realizado anteriormente, e foi graças à nova gestão, que o município foi contemplado com os benefícios financeiros, sociais e econômicos desta legalização.

A capacitação e formação da equipe de trabalhadores que realizavam os serviços internos e externos da repartição podem serem vistos como um processo inovador, pois a secretária está sempre preocupada em capacitar os membros para que estes possam realizar serviços de qualidade e promover eventos que agradem o público local, alavancando o processo cultural local. Esta pode ser conceituada como inovação incremental, aborda pelo Manual de Oslo (2004) como sendo uma ocorrência gradualmente de melhorias e avanços nos métodos e produtos.

A inovação ocorre também nos serviços prestados aos cidadãos, podendo se enquadrar na inovação de melhoria de Gallouj (2002) e inovações de processos citada no Manual de Oslo (2004), por meio de eventos e programas populares como serestas nas ruas, formação de grupo de cantores e exposições de arte, festivais gastronômicos e de cachaça. Estes eventos, vistos como serviços públicos, visam atrair novos públicos e diversificar a oferta de eventos realizados no município para os cidadãos e ajudando na fomentação econômica local.

Seguindo em busca de novas inovações, a gestora e sua equipe demostraram-se proativos nessa questão, onde foram identificando oportunidades em pequenos detalhes que muitos não conseguiram enxergar. Como exemplo deste podemos destacar a participação em programas de financiamento para atividades culturais como o ICMS Cultural e o Fundo de Participação Municipal que também faz repasses de verba para a secretaria, sendo que este tinha acabado de tomar forma em pouco tempo e se tornou referência para as cidades vizinhas, tanto em moldes organizacionais como em destaque de produção de eventos artísticos graças a esses financiamentos. Sua proatividade e de sua equipe fizeram com que o órgão ganhasse credibilidade perante outras secretarias e órgãos.

O que ocorreu de fato com o estudo de caso em questão foi justamente uma inovação empreendedora, onde ocorreram mudanças no modo como essa era vista no município, e de acordo com os relatos da entrevistada, estruturar o órgão foi até hoje o maior desafio de toda a sua carreira e os frutos produzidos com os novos serviços e o aperfeiçoamento de muitos já existentes são fatores motivacionais que a fazem seguir sempre em busca de melhores resultados para o órgão e consequentemente uma maior satisfação com sua carreira.

\section{Empreendedorismo no setor público}

O empreendedorismo apresenta uma concepção multifuncional, sendo que sua aplicabilidade ocorre tanto em organizações públicas quanto nas redes privadas. Morris e Jones (1999) argumentam que empreendedorismo público é uma metodologia de valor para os cidadãos, de forma a unir recursos públicos e privados para explorar oportunidades sociais. O intraempreendedor, ao explorar as oportunidades que surgem, provocam mudanças constantes no ambiente em que estão, procurando soluções inovadoras para assuntos organizacionais (VALADARES; EMMENDOERFER; MORAIS, 2014). Junto a essa afirmação, foi 
notório que a secretaria passou a desenvolver mais eventos, sendo estes trabalhados com recursos públicos e também com a ajuda de patrocínios privados que ajudaram a investir no âmbito cultural do município, como forma de desenvolvimento social e de expandir oportunidades de negócio local. Esses investimentos mostram que a secretaria de cultura está criando certa credibilidade perante a população e empreendedores privados, promovendo os parceiros investidores e incentivando a economia local.

O empreendedor público não desenvolve o ambiente organizacional sozinho, ele compartilha práticas e experiências com sua equipe, caracterizando um processo baseado na ação coletiva e dialógica, onde a soma dos esforços gera um serviço de qualidade ao cidadão (JOHANNISSON, 1998). Como citado ao longo desse trabalho, as características do empreendedor, de acordo com Hornaday (1982); Meredith, Nelson \& Neck (1982): Timmons (1978) apud Filion (1999) permitem que o empreendedor seja aberto a ouvir a participação de terceiros, sendo estes transmissores da "voz do povo". No diálogo estabelecido com a gestora responsável observou-se uma maior aproximação entra a população e os servidores da secretaria de cultura, sendo que a participação em cursos, oficinas e eventos promovidos pela secretaria passaram a serem mais efetivos pela comunidade e também sofrerão aperfeiçoamentos. Estes aperfeiçoamentos dos eventos promovidos pela secretária partiram dela, sua equipe e da própria população que passou a dialogar mais com o órgão e expor mais suas opiniões.

Em se tratando de participações, estas ocorrem dentro da própria equipe, onde seus auxiliares podem ter total liberdade de expor suas opiniões e realizar atividades, porém estas devem ser repassadas a ela primeiro para que ela acompanhe de perto o que está sendo feito.

Johannisson (1998) define sua opinião contra o empreendedorismo atomístico, aquele que minimiza as ações de cunho coletivo, e assim conclui que o ator que empreende no setor público deverá ser um agente com princípios sociais e com diálogo coletivizado, sendo estas características que incrementam o espírito empreendedor. Para reforçar essa ideia, Lecca e Naccache (2006) afirmam que o esforço que é realizado em conjunto, mobiliza a equipe e desencadeia alianças e mecanismos de cooperação para que haja transformações. Agindo com o foco direcionado para a população, a gestora abriu portas e caminhos para que estes levassem suas demandas até ela e sua equipe, estando sempre receptivos e prontos para atendêlos. Essa abertura para a participação popular foi tão positiva que os programas culturais desenvolvidos pelo órgão foram aprimorados e ganhando maiores destaques no município.

Essa abertura de participação também se tornou uma maneira de conhecer as necessidades e demandas da comunidade, sendo que sozinha ou mesmo com sua equipe tornaria mais difícil diagnosticar a vontade da população. Inovar no modo de obtenção das demandas tornou sua gestão mais eficiente e mais próxima da comunidade.

Essas inovações, através de ações empreendedoras, ocorrem quando o agente empreendedor acrescenta diferenciais nos serviços oferecidos e prestados para a sociedade, agregando valor e qualidade ao serviço prestado. Garcia, Gimenez e Toledo (2008) confirmam essa perspectiva ao afirmar que considera a inovação um instrumento, pelo qual os intraempreendedores (aqueles que trabalham dentro dos limites daquela organização) reconhecem a mudança com ensejo para serviços ou negócios diferentes. Esse reconhecimento de oportunidades, em serviços ou negócios no órgão público, pode ajudar a romper com o que era duradouro e instalado. Para melhor exemplificar tal sustentação, podemos observar os cursos desenvolvidos pela gestora e sua equipe, onde os temas dos cursos são variados e contínuos, ou seja, o 
curso é completo, abrangendo o mais alto nível de qualidade de conhecimento e aprendizagem. Os eventos promovidos como exposições, feiras e shows culturais também possuem diversificações, atendendo a maior quantidade possível de pessoas com gostos variados, além de promover a geração de renda para a população com os espaços reservados para a comercialização de alimentos e produtos artísticos.

Pensar e promover o desenvolvimento local também é função do empreendedor inovador, sendo que anteriormente, as atividades culturais que eram minimamente desenvolvidas no município não tinham como pilar principal a promoção de benefícios econômicos para a comunidade. Atualmente, novas oportunidades foram abertas à população graças à visão coletiva da gestora da Secretaria, argumentando que promover a cultura em um município não é simplesmente o fato de atrair títulos de destaque para o município e promover cursos, oficinas e eventos, e sim transmitir valores e ensinamentos culturais para que os envolvidos sintamse mobilizados por tal e passem a diante. A inovação nesse sentido vem alinhada junto a ação empreendedora, quando a gestora passou a identificar maiores oportunidades de promover o desenvolvimento econômico local e inovou abrindo novos mercados para os interessados.

Ao se tratar de desenvolvimento econômico, foi bastante ressaltado que a secretária não carrega em sua gestão o princípio da lucratividade e sim da promoção da lucratividade em modos econômicos e culturais para a população, incentivando-as a participarem de feiras, de produção de produtos artesanais e alimentícios, na construção de carreira de músicos, oficinas de aprendizados e outras atividades que podem gerar lucro para a própria população, gerando o desenvolvimento social.

Andrade, Lima e Borges (2014) conceituam as ações empreendedoras como um fenômeno observável em organizações públicas, como é o caso desse trabalho, sendo identificadas através de oportunidades, bem como nos processos de transformações.

Dessa forma conseguimos visualizar que na Secretaria, as oportunidades vêm demandas pela população ou até mesmo por uma necessidade e assim as ações ocorrem em cima destas problemáticas, resultando em novos ou remodelados produtos, serviços, modelos, maneiras associadas ao crescimento deste e o aumento da competitividade.

\section{CONSIDERAÇÕES FINAIS}

O artigo relata práticas de inovação e de empreendedorismo público vivenciados pela Secretaria de Cultura de uma cidade localizada no sul de Minas Gerais. Segundo Gallouj (2002) inovar é criar um serviço ou produtos ou até mesmo aperfeiçoa-lo, tal fato pode ser observado na secretaria de Cultura, onde inovouse ao desenvolver novos serviços colocados à disposição da comunidade e aperfeiçoou aqueles que já existiam, atraindo bons resultados para o órgão.

Já o empreendedorismo público foi desenvolvido pelos atores da Secretaria de Cultura, a partir das mudanças realizadas no órgão, como a legalização (projeto de lei), a nova organização interna, estruturada com uma equipe escalonada para as atividades com a supervisão da gestora e com o aperfeiçoamento desta equipe com os cursos e palestras promovidos. Segundo Valadares, Emmendoerfer e Morais (2014) um traço marcante de empreendedor é justamente provocar constantes mudanças, tanto no ambiente em que se encontra quanto para as soluções dos problemas existentes no ambiente, o que foi observado na secretaria estudada. 
No setor público o foco é o bem comum, assim o agente de mudança, no caso a secretária, deve-se pautar na promoção de ações que promovam a sociedade e não a autopromoção. Ou seja, o empreendedor público deve sempre visar o que é melhor para atender as demandas da sociedade, e caso esta não coincida com sua vontade pessoal, ele deverá ser imparcial e atender as solicitações da comunidade.

Em se tratando do potencial do empreendedorismo público, este relaciona-se à adoção de técnicas de proatividade e inovação, pelos agentes responsáveis por desenvolver o empreendedorismo e adequá-las ao contexto local. Tal fato pode contribuir para o alcance de uma maior efetividade da organização pública, no que diz respeito a prestação de serviços públicos ao cidadão. Assim, o comportamento do empreendedor público auxilia a organização a ser mais flexível, dinâmica e focada nos resultados. Para que este fato se concretize, é necessário que seja desenvolvido a cultura empreendedora na organização pública, a qual está presente no caso analisado. Foi por meio dela, possível diagnosticar que para ser um empreendedor bemsucedido é preciso afastar medos e incertezas para que este possa ter sucesso e capacidade de estar inovando a cada momento. Também é notório que para o empreendedorismo ser eficiente no serviço público é preciso adaptar a resistência e burocracia, os quais retardam o processo de inovação e melhoria. Concluise que o empreendedorismo público contribui para maior dinamicidade, flexibilidade e foco dentro da organização pública.

Sugere-se que estudos na área de participação social como forma de contribuição para o sucesso do empreendedorismo público, ou estudos de revisão das literaturas existentes sobre empreendorismo e inovações com uma perspectiva crítica sobre o assunto sejam desenvolvidos de forma a complementar tais estudos sobre o tema descrito nesse trabalho.

\section{REFERÊNCIAS}

ANDRADE, D. M.; LIMA, J. B e BORGES, A. F. Ações Empreendedoras em Empresas Familiares: Um Estudo Sob a Ótica de Oportunidades, Inovação e Aprendizagem. In: VIII Encontro de Estudos em Empreendedorismo e Gestão de Pequenas Empresa, Brasil, 24 a 16 de março de 2014.

BARDIN, L. Análise de conteúdo. Lisboa: Ed. 70, 2007.

BUENO, A. M., LEITE, M. L. G., PILATTI, L. A. Empreendedorismo e comportamento empreendedor: como transformar gestores em profissionais empreendedores. IN: XXVI Encontro Nacional de Engenharia de Produção. Florianópolis, Santa Catarina, Brasil, 03 a 05 de nov. de 2004.

CURRIE, G.; HUMPHREYS, M.; UCBASARAN, D.; MCMANUS, S. Entrepreneurial leadership in the English public sector: Paradox or possibility? Public Administration, v. 86, n4, p. 987-1008, 2008.

DORNELAS, J. C. A. Empreendedorismo Corporativo: como ser empreendedor, inovar e se diferenciar em organizações estabelecidas. Rio de Janeiro: Elsevier, 2003.

DRUCKER, P. F. Innovation and Entrepreneurship: Practice and Principles. Londres: Butterworth-Heinemann, 1985.

FERNANDES, D. V.; DER HEYDE \&SANTOS; C. P. Orientação empreendedora:um estudo sobre as conseqüências do empreendedorismo nas organizações. Revista RAE-eletrônica, São Paulo, v.7, n.1, Art. 6, jan./jun. 2008.

FILION, L. J. From Entrepreneurship to Entrepronology, paper presented at the 42nd ICSB World Conference, June, San Francisco, 1997.

FILION, L. J. Empreendedorismo: empreendedores e proprietários-gerentes de pequenos negócios. Revista de Administração v. 34, n. 2, p. 05-28, Abril/Junho 1999.

GALLOUJ, F. Innovation in the Service Economy: the new wealth of nations. Cheltenham, UK: Edward Elgar Publishing Limited, 2002.

GARCIA, U.L.; GIMENEZ, F.A. P.; TOLEDO, A. Ações e comportamento intraempreendedores: uma escala de mensuração. In: $V$ ENCONTRO DE ESTUDOS SOBRE EMPREENDEDORISMO E GESTÃO DE PEQUENAS EMPRESAS. São Paulo. 2008. 
JOHANNISSON, B. Entrepreneurship as a Collective Phenomenon. RENT XII, Lyon, França, 1998.

KIRK, J.; MILLER, M. L. Reability and validity in qualitative research. Newbury Park, California: Sage Publication, 1986.

Manual de Oslo, desenvolvido pela Organização para Cooperação Econômica e Desenvolvimento (OCDE) e publicado no Brasil pela Financiadora de Estudos e Projetos (FINEP). Disponível em: www.finep.gov.br/dcom/brasil inovador /menu.html. Acesso em: 15 de abril de 2015.

MATTAR, F. N. Pesquisa de marketing: metodologia, planejamento, execução, análise. São Paulo: Atlas, 1993. v.1.

MCCLELLAND, D. C. The Achieving Society. Nova York: Irvington Publishers, 1961

MOTA COELHO, M. M. O intraempreendedorismo e a inovação na Gestão Pública Federal. Revista do Serviço Público, v. 61, p. 233-247, 2010.

MORRIS, M. H.; JONES, F. F. Entrepreneurship in established organizations: the case of the public sector. Entrepreneurship Theory and Practice, v. 24. n. 1. p. 71-91, 1999.

OLIVEIRA, D. C.; GUIMARÃES, L. O.; Perfil empreendedor e ações de apoio ao empreendedorismo: o NAE/Sebrae em questão. p. 3-5. 2004

OSBORNE, D.; GAEBLER, T. Reinventing government : How the entrepreneurial spirit is transforming the public sector . New York, NY: Plume, 1992.

PINCHOT III, G. Intrapreneuring: porque você não precisa deixar a empresa para tornar-se um empreendedor. São Paulo: Harbra, 1985

SCHUMPETER, J. A. Economic Theory and Entrepreneurial History, 1949, Changeand the Entrepreneur. Revista Brasileira de Inovação, São Paulo, vol. I, n. 2, jul./dez. 2002

SADLER, R. J. Corporate entrepreneurship in the public sector: the dance of the chameleon. Australian Journal of Public Administration, v. 59, n. 2, p. 25-43, 2000.STAKE, R.E.. Case studies. In: N.K. DENZIN e Y. LINCOLN (eds.), Handbook of qualitative research. 2 ed. Thousand Oaks, Sage.2000

VALADARES, J. L.; EMMENDOERFER, M. L.; ALVES, R. C. M. e MORAIS, M. C. A. O Fenômeno do Empreendedorismo Público: Um Ensaio sobre a Aplicabilidade desse Construto na Administração Pública Brasileira. In: XXXVI Encontro da ANPAD, Brasil, 22 a 26 de setembro de 2012.

VALADARES, J. L.; EMMENDOERFER, M. L.; MORAIS, M. C. A. . Polissemias do Empreendedorismo no Setor Público. In: XXXVIII Encontro da ANPAD, Brasil, 13 a 17 de setembro de 2014.

VERGARA, S. C. Método de Pesquisa em Administração. 2.Ed. São Paulo: Altas, 2006. 